\title{
A small, unusual theropod (Dinosauria) femur from the Wealden Group (Lower Cretaceous) of the Isle of Wight, England
}

\author{
Darren Naish, Portsmouth
}

With 4 figures

NAish, D. (2000): A small, unusual theropod (Dinosauria) femur from the Wealden Group (Lower Cretaceous) of the Isle of Wight, England. - N. Jb. Geol. Paläont. Mh., 2000: 217-234; Stuttgart.

\begin{abstract}
A complete femur of a small theropod dinosaur from the Wessex Formation (Wealden Group, Lower Cretaceous) of the Isle of Wight, England, is described for the first time. In differing from other Wealden Group theropod femora, it augments Wealden Group theropod diversity. The morphology of the anterior trochanter suggests that it is not of a tetanuran. However, it could represent a derived form that has modified typical tetanuran morphology, like the North American oviraptorosaur Microvenator, which it resembles. Extensive pitting on the proximal end implies that it was a pathological or juvenile individual.
\end{abstract}

Zusammenfassung: Aus der Wessex-Formation (Wealden) der Insel Wight wird erstmals ein vollständiges Theropoden-Femur beschrieben. Nach der Form des vorderen Trochanters gehört es nicht zu einem Tetanuren; es könnte aber von einer abgeleiteten Art mit einer modifizierten Tetanuren-Morphologie gehören, ähnlich wie der nordamerikanische Microvenator, an den es erinnert. Grübchen-Strukturen auf dem proximalen Ende deuten an, daß es sich um ein pathologisches oder juveniles Tier handelte.

\section{Introduction}

The Wealden Group (Berriasian-Aptian) rocks of southern England yield a diverse dinosaur fauna that includes sauropods (Ostrom 1970, CHARIG 
1980, Blows 1995), ankylosaurs (Blows 1987, Pereda-Suberbiola 1993), (BARRETT \& UPCHURCH 1995) and ornithopods (GALTON 1974, 1975, NORMAN 1980, 1986, 1987). Theropods are represented by a large allosauroid (HuTt et al. 1989, 1996), the spinosauroid Baryonyx (CHARIG \& MILNER 1986, 1997), the probable compsognathid Aristosuchus (OwEN 1876, SEELEY 1887a), a new taxon of large, long-legged coelurosaur (HUTT et al. in prep.), and a variety of indeterminate forms (OwEN 1857, NAISH in press).

Thus far 12 specific names have been created for the fragmentary small theropods discovered in the English Wealden Group (Fox 1866, OwEN 1876, SEELEY 1882, 1887a 1887 b, 1888, LYDEKKER 1888, 1889, 1891, HUENE 1923, PAUL 1988). Five of these names are junior synonyms, and of the remaining seven, all are nomina nuda or nomina

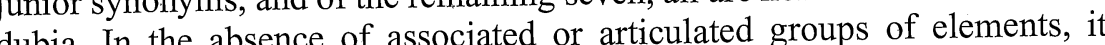
remains impossible to establish synonymy of any or all of these seven remaining names. Despite this, it has at times been suggested that most or all are referable to Calamospondylus oweni or Aristosuchus pusillus (OSTROM 1970, NORMAN 1985, 1990, KIRKLAND et al. 1998), the two earliest named of them all.

Several isolated small theropod elements, predominantly limb bones, have never been awarded their own names but have been referred to taxa have neverial such as vertebrae previously established on noncomparable material such as vertebrae (LYDEKKER 1891, GALTON 1973). A number of Wealden Group theropod elements have never been described and form the focus of an ongoing study (NAISH 1998a, in press). MIWG 6214, the specimen described in this paper, is one such new specimen.

Specimens described here are housed in the Museum of Isle of Wight Geology, Sandown Isle of Wight (MIWG), and the Natural History Museum, London (BMNH)

\section{Note on terminology}

CARPENTER \& KIRKIAND (1998) have recently argued that two anatomical terms that apply to the dinosaurian femur, the greater trochanter and lesser trochanter, are incorrect on the basis of homology. GrEGORY (1918) had previously noted that use of these terms was inaccurate, but very few workers had followed him. Following GREGORY's (1918) and CARPENTER \& KIn dinosaurian lesser trochanter is not homologous with the lesser trochanter of some other reptiles and mammals and hould be called the anterior trochanter. Furthermore, the structure frequently described as the greater trochanter truly represents the crista trochanteris; the true greater trochanter is the structure on the proximolateral surface of the shaft (GREGORY 1918, CARPENTER \& KIRKLAND 1998).

In the interest of promoting future stability, and of recognising anatomical terms based on true homology, this revised terminology is used here.

\section{Material}

MIWG 6214 is a complete and well preserved left femur collected by K. MiNTER in November 1986 from the Lower Plant Debris Bed in the Wessex Formation (Wealden Group, Lower Cretaceous) between Compton and Hanover Point, Isle of Wight Prior to a very brief mention in NAISH (1998 b) it had not been previously referred to in print.

The entire area of the caput and crista trochanteris and the proximal part of the anterior trochanter is heavily pitted in MIWG 6214. This might indicate that it is from a juvenile. However, other theropod specimens known to be of juvenile or even embryonic age reveal fully ossified limb bones (CURRIE \& PENG 1994, NorELL et al 1994). An alternative possibility is that the heavily pitted proximal end of MIWG 6214 is pathological. If the latter is correct, then the size of MIWG $6214(123 \mathrm{~mm}$ long, measured along lateral condyle) shows that it was a small dinosaur, and, if adult, possibly among the smallest of all non-avian theropods known. MIWG 6214 cannot be assigned to any theropod taxon for which femora are known and is highly distinctive, especially in the morphology of its anterior trochanter.

\section{Description}

MIWG 6214 is gently sigmoidal in lateral view (Fig. 1a). The maximum width of the proximal end of MIWG 6214 is $15.4 \mathrm{~mm}$ and the maximum distal width is $21 \mathrm{~mm}$. At midshaft, the craniocaudal width of the bone is 12 $\mathrm{mm}$ and the mediolateral width is $11.5 \mathrm{~mm}$. Examination of MIWG 6214's proximal end under a microscope proved that pitting there is accentuated by some breakage. It has also undergone some restoration.

A well-defined subspherical or elliptical caput is not evident, though the orientation of the neck shows that the caput would have projected medially at an angle of approximately 40 degrees to the long axis of the femoral shaft (Fig. 2a). There is no overhang of the neck by the caput as is the case in some other theropods. A medial projection in this position appears to represent part of the broken caput.

Because of the incomplete nature of MIWG 6214's proximal end, there is no clear demarcation of a crista trochanteris. The continuity of the proximal surface, however, is suggestive of a continuous crista trochanteris and femoral head. This condition is seen in allosauroids (CURRIE \& ZHAO 1994) and, among indeterminate Wealden theropods, in an isolated femur from the Isle of Wight described by GALTON (1973). 


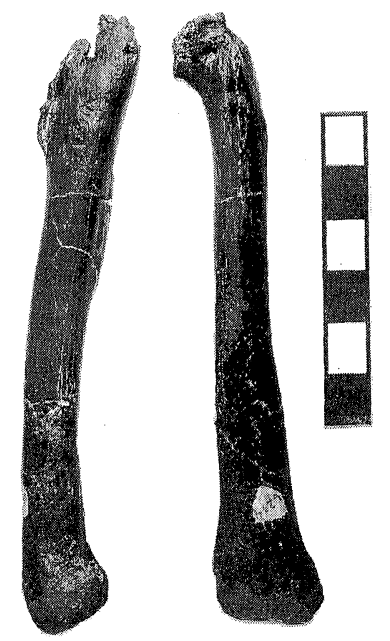

Fig. 1 Left: MIWG 6214 in left lateral view. Right: MIWG 6214 in cranial view.

MIWG 6214 has a pronounced anterior trochanter that is long and low. The anterior trochanter is clearly demarcated proximally from the femoral shaft by a well-defined notch that undercuts its proximal $3.5 \mathrm{~mm}$ (Fig. $2 \mathrm{~b}, \mathrm{c}$ ). The crest of the anterior trochanter in MIWG 6214 has, for the entire trochanteric length, a rough, irregular texture similar to that of the caput. The crest of the anterior trochanter forms a platform rather than a sharp ridge. It is $3 \mathrm{~mm}$ wide proximally and $1.8 \mathrm{~mm}$ wide distally, and (when seen laterally or medially) has a shallow V-shaped incision about half-way along its length (Fig. $2 b, c)$.

On the lateral side, the anterior trochanter is flush with the femoral shaft and forms a gently convex, smooth surface with it, while, on the medial side, the base of the trochanter and the part of the shaft to which it attaches are gently concave. Proximally, on the medial surface of the anterior trochanter, there is a prominent foramen located within an elliptical depression. Theropod anterior trochanters often have a foramen at this location (CURRIE \& ZHAO 1994).

Significantly, the anterior trochanter of MIWG 6214 is consistently the same height $(3 \mathrm{~mm}$ ) along its entire $21 \mathrm{~mm}$ length, an unusual feature that invites comparison with the anterior trochanters of other theropods.
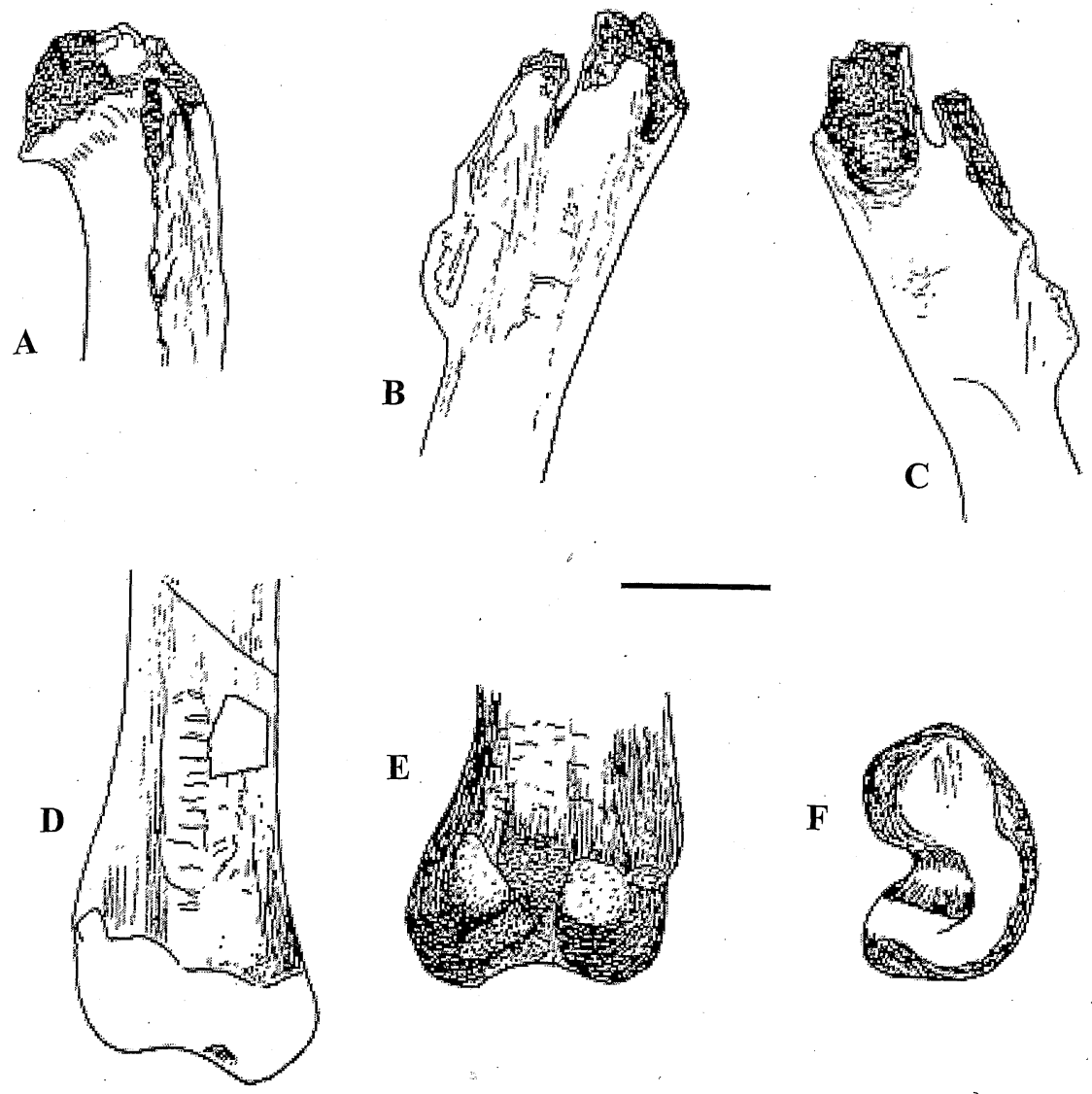

F

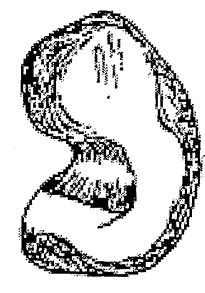

Fig. 2. Proximal end of MIWG 6214 in cranial (A), lateral (B), and medial (C) views Distal end of MIWG 6214 in cranial (D), caudal (E), and distal (F) views. Scale bar $=1 \mathrm{~cm}$.

The fourth trochanter in MIWG 6214 is a low but sharp ridge that projects mediocaudally. It is clearly not of an ornithischian morphology - an identity that has to be eliminated because MIWG 6214 lacks an extensor groove, as do some of the smaller ornithischians. If an imaginary line joining the 
femur's cranial surface to its caudal surface is visualised, the most proximal point of the fourth trochanter in MIWG 6214 is located a few mm distal to the distal end of the anterior trochanter. The fourth trochanter then extends distally for $21 \mathrm{~mm}$. Its axis is almost straight.

The intercondylar groove separating the distal condyles of MIWG 6214 is very shallow. The two distal condyles are smoothly rounded; the lateral condyle is larger and extends further ventrally than does the medial condyle (Fig. 2d). The lateral condyle also extends somewhat further caudally than does the medial condyle and has a slightly swollen appearance that reminds one of the blocky protuberance noted in Allosaurus by MADSEN (1976). WELLES (1984) called this structure the ectocondylar tuber.

Another feature of MIWG 6214's distal end is a medial extension that projects diagonally from the otherwise straight edge of the femur to meet with the top of the medial condyle. Viewed from the medial side, this extension appears as a smooth, raised ridge that meets the middle of the dorsal edge of the medial condyle (Fig. 2 d). It is here interpreted as a poorly developed mediodistal crest.

The caudal surface of MIWG 6214 bears a distinct, deep popliteal fossa within which the bone surface is pitted (Fig. 2 e). A shallow groove runs from the popliteal fossa a short distance proximally. There is also a U-shaped extension on the distal articular surface of the femur that runs diagonally from the intercondylar groove beneath the lateral condyle toward the caudolateral corner of the medial condyle (Fig. 2f). There is no crista tibiofibularis.

\section{Discussion}

MIWG 6214 is an intriguing specimen that is hard to place in a phylogenetic context. It may also be potentially important in indicating further theropod diversity within the Wealden Group fauna, as it does not seem to represent the same taxon as do the other Wealden Group theropods for which femora are known.

The specimen is clearly from a theropod. Its prominent anterior trochanter, presence of a deflected caput and lack of mediolateral curvature prove it to be dinosaurian. Its ridge-like fourth trochanter shows that it is not a non-thyreophoran ornithischian, while its craniodorsal curvature, gracility, and lack of transversely expanded proximal and distal ends show that it is not from a thyreophoran. The craniodorsal curvature and prominent anterior trochanter of MIWG 6214 also show that it is not from a small or juvenile sauropod.

\section{Comparisons with other Wealden Group theropods}

Given that MIWG 6214 is theropodan, how does it compare with the other theropod femora from the Wealden Group? Two isolated and incomplete theropod femora, the specimens BMNH R5194 and BMNH R36539, and the femora of the holotypes of Neovenator salerii and of Baryonyx walkeri, are available for comparison.

The proximal end of a right femur, BMNH R5194, is known from the Wessex Formation of the Isle of Wight (Fig. 3 a). It has a robust, wing-shaped
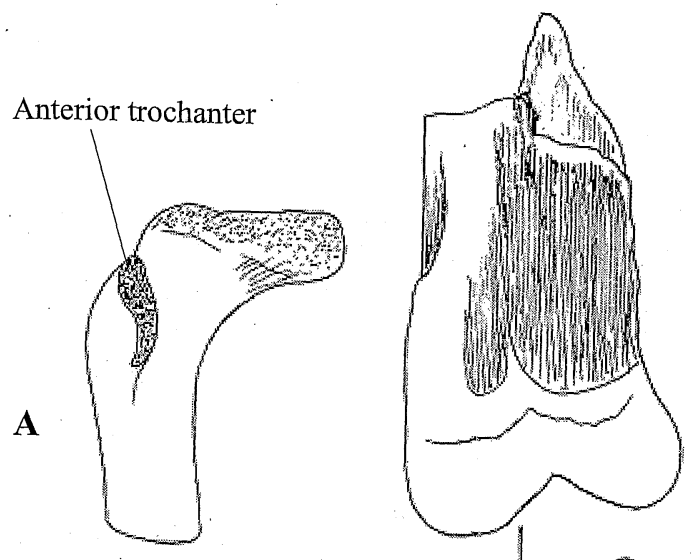

B

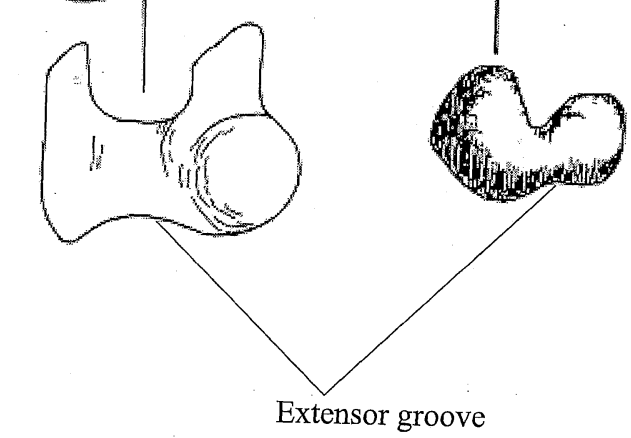

Fig. 3 a: BMNH R5194, a proximal right femur from a small tetanuran, in cranial view. b: BMNH R36539, a distal end of a left femur, in cranial and distal views. c: Distal end of a possible bird femur described by SEELEY (1899), in cranial and 
anterior trochanter, crista trochanteris that is nearly confluent with the caput, and a reduced fourth trochanter that is little more than a raised scar (GALTON 1973). A number of salient differences - the morphology of the anterior trochanter especially - show that BMNH R5194 represents a tetanuran, and is clearly not from the same taxon as MIWG 6214. BMNH R5194 may be referable to the Compsognathidae (NAISH in prep.), and GALTON (1973) suggested that it might belong to Aristosuchus, a taxon regarded here as a Wessex Formation compsognathid.

BMNH R36539, a distal end of a left femur from the Weald Clay of Sussex, is also clearly from a tetanuran and differs in several respects from MIWG 6214. It possesses an extensor groove, a very sharp-edged mediodistal crest, and very pronounced, caudally directed protuberances on its distal condyles (Fig. 3b). The caudal protuberance on the lateral condyle of BMNH R36539 is markedly square-shaped in lateral view, unlike the weakly expressed, rounded protuberance in MIWG 6214. The two are clearly very different and represent different taxa. BMNH R36539 is very similar to the distal femur of the North American coelurosaur Nedcolbertia (KIRKLAND et al. 1998) and is tentatively referred to cf. Nedcolbertia.

When MIWG 6214 is viewed proximally, the anterior trochanter curves medially. This is in contrast to the plate-like or sheet-like anterior trochanter of allosauroids in which, when the femur is viewed proximally, the trochanter projects cranially at a right angle to the acetabulum (MADSEN 1976, CURRIE \& ZHAO 1994). The long and low, medially curving anterior trochanter of MIWG 6214 therefore excludes it from the Allosauroidea, thus it is probably not a juvenile of Neovenator salerii.

MIWG 6214 also does not appear to represent a juvenile of Baryonyx walkeri as this taxon also does not possess a long and low, elongate anterior trochanter (CHARIG \& MILNER 1997). The femur of the African baryonychid Suchomimus is described as having a blade-shaped anterior trochanter (SERENO et al. 1998).

\section{Problematic features 1. Absence of an extensor groove}

Unlike BMNH R36539, and the femora of Neovenator and Baryonyx, MIWG 6214 lacks an extensor groove, a structure apparently common to tetanurans. Might the absence of an extensor groove in MIWG 6214 therefore indicate that it is not tetanuran? Assuming that the specimen is tetanuran, it could be argued that its lack of an extensor groove is due to its small size. However, presence of the extensor groove does not seem to be a sizedependent feature as it is evident in small tetanurans (PAUL 1988, Novas 1997, MARTILL et al., in prep) including birds (BAUMEL 1979), even juvenile passerines (pers. obs.). However, an extensor groove is absent in Mononykus olecranus (PERLE et al. 1994, NovAs 1996a). Because less derived alvarezsaurids do possess an extensor groove (NovAs 1996a, 1997), this represents an autapomorphic loss of this character within Alvarezsauridae. MIWG 6214 does not compare with Mononykus as this taxon is still clearly tetanuran in the morphology of its proximal end: it has a short, proximally located anterior trochanter that is connected to the greater trochanter (PERLE et al. 1994, Novas 1996a).

However, presence or absence of the extensor groove may be ontogenetic as one is absent in the holotype femur of Microvenator celer, a juvenile oviraptorosaur (MAKOVICKY pers. comm.). This means that absence of the extensor groove in MIWG 6214 should not be relied upon as a character of systematic importance.

\section{Problematic features 2. Morphology of the anterior trochanter}

A number of descriptive terms have been applied to theropod anterior trochanters, including wing-like, blade-like, spike-like and finger-like (GAuthier 1986, BARSBold et al. 1990, Norman 1990, SERENo et al. 1996, CARPENTER 1997). The term wing-like with respect to anterior trochanters originated with GAUTHIER (1986). It refers to a parallelogram-shaped trochanter that is attached to the femoral shaft by one of its edges. SERENO et al. (1996) have recently referred to the same morphology as blade-shaped. Such terms and definitions do not describe the anterior trochanter of MIWG 6214.

Herrerasaurids and coelophysoids retain the short anterior trochanter with trochanteric shelf that is primitive for dinosauriforms (GAUTHIER 1986, NOVAS 1996b, SERENO \& ARCUCCI 1994). Neoceratosaurs have an anterior trochanter perhaps intermediate between the short spike of coelophysoids and the wing-like plate or sheet of allosauroids (Fig. 4a), being a distally located flange that is proximodistally short and not wing-shaped (GILMORE 1920, Bonaparte et al. 1990, CARPenter 1997) (Fig. 4b). Neither of these morphologies resembles the long and low anterior trochanter of MIWG 6214.

GAUTHIER's (1986) use of the wing-like anterior trochanter as a character unique to tetanurans has been corroborated by other workers (BENTON 1990, SERENo et al. 1996, SuEs 1997, HARris 1998) and can be regarded as an unambiguous tetanuran synapomorphy. The fact that MIWG 6214 lacks a wing-like anterior trochanter may indicate that it is not a tetanuran, but as other features imply that it is perhaps pathological or juvenile, it appears unwise to regard this as unequivocal. The presence of a non-neoceratosaurian non-tetanuran theropod in the Wealden Group (and, indeed, in the 


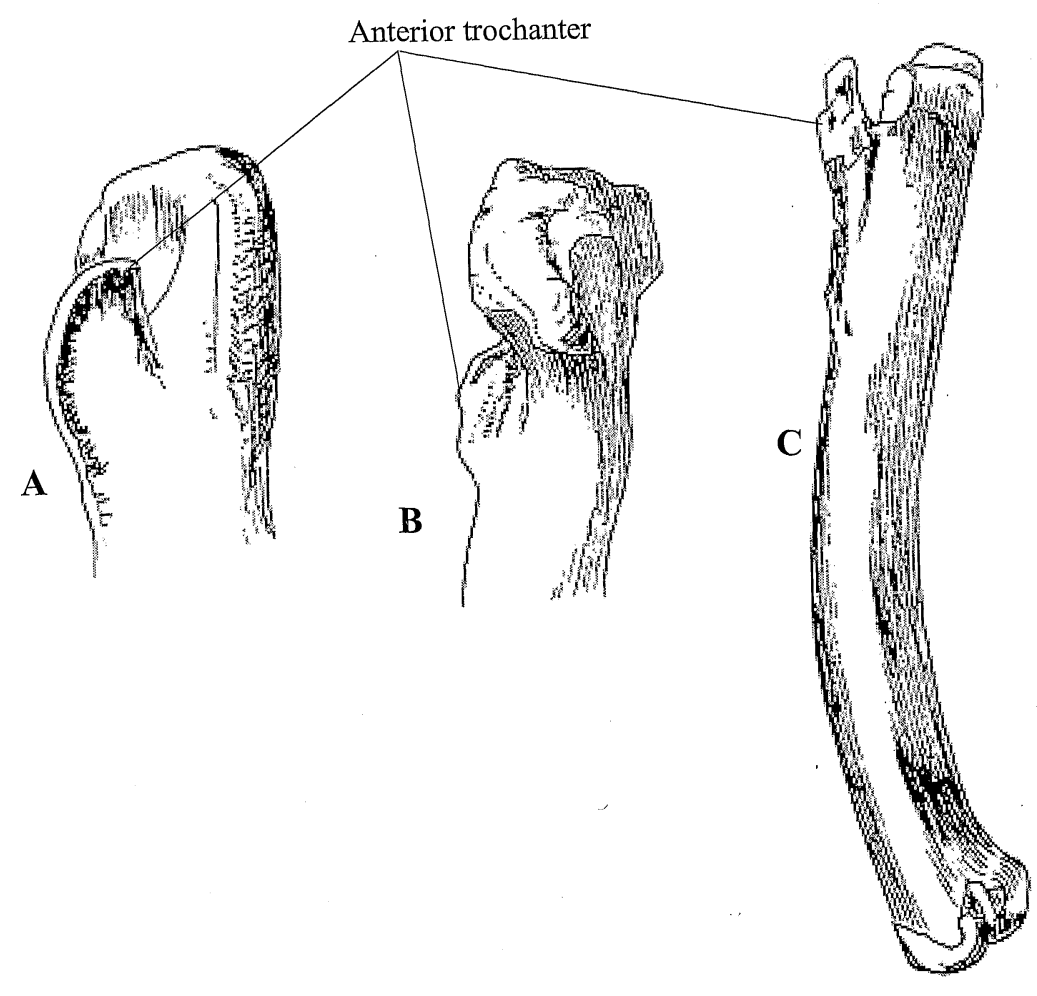

Fig. 4 a: Lateral view of the proximal femur of Sinraptor. b: Medial view of the proximal femur of Ceratosaurus. c: Lateral view of the femur of Microvenator. Not to scale.

Lower Cretaceous) would be highly significant as such theropods are otherwise restricted to the Triassic and Lower Jurassic.

A number of tetanuran clades modified the shape of their anterior trochanter, such that its morphology deviates from the wing-like shape, and comparisons with MIWG 6214 are therefore warranted.

\section{Comparisons with maniraptorans, troodontids and oviraptorosaurs}

For example, one designation that might otherwise seem favourable in view of its small size is that MIWG 6214 represents a maniraptoran. The correct and restrictive definition of Maniraptora is used here (all theropods closer to birds than to Ornithomimus (GAUTHIER 1986, Holtz 1996)), rather than an incorrect previous, much more inclusive use of the term (HoLtz 1994). Amongst maniraptorans, the robust anterior trochanter of Deinonychus is very unlike that of MIWG 6214 in its proximity to the crista trochanteris and its lack of a projecting crest (OSTROM 1976a). A posterior trochanter is evident in Archaeopteryx as it is in Deinonychus (Ostrom 1976 b), Unenlagia (Novas \& PuerTA 1997) and enantiornithine birds (ChIAPPE 1991, ChiAPPE \& CALVO 1994, BufFETÁtT 1998), but there is no such structure in MIWG 6214.

The presence of a fourth trochanter in MIWG 6214 might seem to immediately disqualify it from membership of the Maniraptora, if the assertions of certain workers are to be believed. OsTROM (1976a) described the femur of Deinonychus as lacking a fourth trochanter. GAUTHIER (1986) and HolTz (1994) coded dromaeosaurids as lacking a fourth trochanter. More recently NovAs (1996a), SuEs (1997) and MAKOVICKY \& SuEs (1998) have drawn attention to the presence in at least some dromaeosaurids of a fourth trochanter.

It is therefore the features of the proximal end, and not of the insertion area for the caudofemoralis longus, that are of importance in showing that MIWG 6214 is not a maniraptoran. This may be significant because an imperfect distal femur bearing a strong similarity to MIWG 6214, discussed below, has previously been regarded as avian (SEELEY 1899).

Troodontid femora are like those of dromaeosaurids, Unenlagia and Archaeopteryx in having a very proximally placed anterior trochanter that is almost continuous with the crista trochanteris (CURRIE \& RUSSELL 1988, CURRIE \&. PENG 1994). Troodontid anterior trochanters that have been illustrated are robust bumps that cannot be defined as wing-like. SUES (1997), who otherwise coded the anterior trochanters of theropods as spikelike (0) or wing-like (1), coded troodontids as '?'. Again, however, the bumpshaped anterior trochanters of troodontids differ markedly from MIWG 6214's peculiar anterior trochanter, thereby providing no indication that MIWG 6214 should belong to this group. Oviraptorosaurs have a pronounced anterior trochanter that, in the Upper Cretaceous taxa Oviraptor and Ingenia, is a robust finger-shaped projection separated from the crista trochanteris by a narrow cleft (BARSBOLD et al. 1990). This is markedly different from the long, low, wing-like anterior trochanter of MIWG 6214.

MAKOvicky \& SuES (1998) show that Microvenator celer from the Cloverly Formation (Lower Cretaceous) is either the oldest known oviraptorosaur or the sister-taxon to Oviraptorosauria, as was suggested by CURRIE \& RUSSELL (1988). Microvenator shares with other oviraptorosaurs a 
prominent anterior trochanter: indeed, OsTROM (1970) writes that it is more prominent than that of any other theropod with which he is familiar. What is interesting in the context of MIWG 6214's identity is that the femur of Microvenator exhibits a long and low accessory trochanteric crest distal to its finger-shaped anterior trochanter. This recalls the anterior trochanteric morphology of MIWG 6214, as does the proximal notch that undercuts the anterior trochanter of Microvenator (Fig. 4c). The femur of Microvenator is also very like MIWG 6214 in its general proportions.

However, a number of differences are evident. MAKOvICKY \& SUES (1998) describe the Microvenator crista trochanteris as 'broadly separated from the head by a saddle-shaped sulcus'. There is no indication of such a sulcus in MIWG 6214, though admittedly this area is broken and partially reconstructed. Also, though the anterior trochanter of MIWG 6214 displays the same broken appearance as does the caput and crista trochanteris, it does not appear possible for the anterior trochanter to have projected dorsally in the same kind of tall, finger-shaped crest as does that of Microvenator (Ostrom 1970, Makovicky \& SuEs 1998). A relationship between Microvenator and MIWG 6214 might be precluded, moreover, by the absence of a fourth trochanter in Microvenator (Ostrom 1970, MAKOvickY \& SuES 1998).

The significance of these differences is hard to evaluate, as such features are prone to a great deal of intraspecific variation in theropods. Similarly, it seems unwise at this stage to regard the identity of MIWG 6214 as resolved. Nevertheless, MIWG 6214 does resemble the femur of Microvenator, and future discoveries may demonstrate the presence of this taxon, or of a closely related one, in the Wealden Group.

\section{A ?bird femur similar to MIWG 6214}

While the affinities of MIWG 6214 remain unresolved, it is of note that a femoral fragment of very similar general appearance was described and illustrated by SEELEY (1899). The fragment (Fig. 3c), a distal femur $20 \mathrm{~mm}$ long discovered in Wealden Group rocks of Cuckfield, Sussex, was regarded by SEELEY (1899) as avian, and with its closest affinities to Colymbus (a junior synonym of the podicepidiform Podiceps).

However, this fragment does differ from MIWG 6214 in clearly possessing an extensor groove despite its very small size (in birds, this structure is usually termed the rotular groove or sulcus patellaris (BAUMEL 1979)). This difference indicates that the similarities between the two specimens are superficial and they do not represent the same taxon.

\section{Conclusions}

MIWG 6214 is a theropod femur that does not represent the same taxon as BMNH R5194 or BMNH R36539, the two other Wealden Group femoral fragments. It is not referable to Neovenator or to Baryonyx. MIWG 6214 therefore indicates the presence of another type of small theropod in the English Wealden Group. The fact that more than one small theropod is present in the Wealden Group is also evident from other overlapping elements including tibiae and sacra (NAISH in press).

The absence of both a wing-shaped anterior trochanter and an extensor groove imply that MIWG 6214 does not belong to a tetanuran, but in view of features that might indicate juvenility or pathology the possibility exists that it represents an unusual, juvenile or deformed tetanuran. Other types of tetanuran - namely maniraptorans, troodontids and oviraptorosaurs - are known to have modified either the morphology of the anterior trochanter, or the presence of the extensor groove, so MIWG 6214 may well represent a derived tetanuran. However, MIWG 6214 is not referable to the Troodontidae or the Maniraptora (sensu Holtz (1996)), even though it bears similarities to the femora of a possible Wealden Group bird. It does resemble, however, the femur of the primitive oviraptorosaur Microvenator and future discoveries may show that it is either referable to it, or representative of a closely related taxon.

Presently unknowable is whether MIWG 6214 represents the same taxon as some of the other isolated theropod elements known from the Wealden Group. Aristosuchus pusillus, Calamosaurus foxi and Thecocoelurus daviesi are all representative of coelurosaurs, as are the isolated tibiae BMNH R 186 and MIWG 5137 (NAISH in prep.). However, the sacrum that is the type for Ornithodesmus cluniculus (SEELEY 1887b), though tentatively regarded in a recent redescription (Howse \& MILNER 1993) as troodontid, may not be tetanuran as some of the features evident in this specimen are reminiscent of those seen in non-tetanuran theropods. Further study or discovery may therefore verify the presence of non-tetanurans in the English Wealden Group.

The precise affinities of MIWG 6214 remain unresolved, and it is here regarded as Theropoda indet.

\section{Acknowledgements}

I thank Steve Hutt (MIWG, Sandown) for access to MIWG 6214, and SANDRA CHAPMAN (BMNH, London) for access to the Wealden Group theropod collection at the Natural History Museum. OlIVER RaUHUT (Bristol) provided helpful insights into the problematic identity of MIWG 6214. PeTE MAKOVICKY (AMNH, New York) Stig Walsh, Dave Martill (Portsmouth) and Tracy Ford (Poway, Calif.) provided 
helpful comments. BОв LOVERIDGE kindly assisted with photography. This work was supported by a scholarship from the University of Portsmouth.

\section{References}

BARRETT, P. M. \& UPCHURCH, P. (1995): Regnosaurus northamptoni, a stegosaurian dinosaur from the Lower Cretaceous of southern England. - Geol. Mag., 132: 213-222.

BARSBOld, R., MARYANSKa, T. \& Osmolska, H. (1990): Oviraptorosauria. In: WeISHAMPEL, D. B., Dodson, P. \& OsmolskA, H. (Eds.): The Dinosauria. - p. 249 258, Berkeley (Univ. Calif. Press).

Baumel, J. J. (1979) Osteologia. - In: Baumel, J. J., King, A. S., LuCAs, A. M., Breazile, J. E., \& Evans, H. E. (Eds.): Nomina Anatomica Avium: 53-121; London (Academic Press).

BENTON, M. J. (1990): Origin and interrelationships of dinosaurs. In: WEISHAMPEL, D. B., Dodson, P. \& Osmolska, H. (Eds.): The Dinosauria: 11-30; Berkeley (Univ. Calif. Press).

Blows, W. T. (1987): The armoured dinosaur Polacanthus foxi from the Lower Cretaceous of the Isle of Wight. - Palaeontology, 30: 557-580.

- (1995): The Early Cretaceous sauropod dinosaurs Ornithopsis and Eucamerotus from the Isle of Wight, England. - Palaeontology, 38: 187-197.

Bonaparte, J. F., Novas, F. E. \& Coria, R. A. (1990): Carnotaurus sastrei Bonaparte, the horned, lightly built carnosaur from the Middle Cretaceous of Patagonia. - Contrib. Sci., Natur. Hist. Mus. Los Angeles Cty., 416: 1-41.

BUFFETAUT, E. (1998): First evidence of enantiornithine birds from the Upper Cretaceous of Europe: postcranial bones from Cruzy (Herault, southern France). Oryctos, 1: 131-136.

CARPENTER, K. (1997): A giant coelophysoid (Ceratosauria) theropod from the Upper Triassic of New Mexico, USA. - N. Jb. Geol. Paläont. Abh., 205: 189-208; Stuttgart.

CARPENTER, K. \& Kirkland, J. I. (1998): Review of Lower and Middle Cretaceous ankylosaurs from North America. - In: LuCAs, S. G., KIRKLAND, K. I. \& EsteP, J. W. (Eds.): Lower and Middle Cretaceous Terrestrial Ecosystems., New Mexico Mus. Natur. Hist. Sci., Bull., 14: 249-270.

ChARIG, A. J. (1980): A diplodocid sauropod from the Lower Cretaceous of England. In: JACOBS, L. L. (Ed.): Aspects of Vertebrate History: 231-244; Flagstaff (Museum of Northern Arizona Press).

Charig, A. J. \& Milner, A. C. (1986): Baryonyx, a remarkable new theropod dinosaur. - Nature, 324: 359-361.

- (1997): Baryonyx walkeri, a fish-eating dinosaur from the Wealden of Surrey. Bull. Natur. Hist. Mus., (Geol), 53: 11-70.

CHIAPPE, L. (1991): Cretaceous avian remains from Patagonia shed new light on the early radiation of birds. - Alcheringa, 15: 333-338.

Chiappe, L. \& Calvo (1994): Neuquenornis volans, a new Late Cretaceous bird (Enantiornithes: Avisauridae) from Patagonia, Argentina. - J. Vert. Paleont., 14: $230-246$.
Currie, P. J. \& Peng (1994): A juvenile specimen of Saurornithoides mongoliensis from the Upper Cretaceous of northern China. - Canad. J. Earth Sci., 30: 2224-2230.

CurRIE, P. J. \& Russell, D. A. (1988): Osteology and relationships of Chirostenotes pergracilis (Saurischia, Theropoda) from the Judith River (Oldman) Formation of Alberta, Canada. Canad. J. Earth Sci., 25: 972-986.

CURRIE, P. J. \& ZHAO, X.-J. (1994): A new carnosaur (Dinosauria, Theropoda) from the Jurassic of Xinjiang, People's Republic of China. - Canad. J. Earth Sci., 30: 2037-2081.

Fox, W. T. (1866): Another new Wealden reptile. - Athenaeum, 2014: 740.

Galton, P. M. (1973): A femur of small theropod dinosaur from the Lower Cretaceous of England. - J. Paleont., 46: 996-1001.

- (1974): The ornithischian dinosaur Hypsilophodon from the Wealden of the Isle of Wight. - Bull. Brit. Mus. (Natur. Hist.), Geol., 25: 1-152.

- (1975): English hypsilophodontid dinosaurs (Reptilia, Ornithischia). - Palaeontology, 18: 741-752.

GATESY, S. M. (1990): Caudofemoral musculature and the evolution of theropod locomotion. - Paleobiology, 16: 170-186.

GAUTHIER, J. (1986): Saurischian monophyly and the origin of birds. - Mem. Calif. Acad. Sci., 8: 1-55.

Gilmore, C. W. (1920): Osteology of the carnivorous Dinosauria in the United States National Museum, with special reference to the genera Antrodemus (Allosaurus) and Ceratosaurus. - Bull. U.S. Nat. Mus., 59: 581-594.

GreGory, W. K. (1918): Note on the morphology and evolution of the femoral trochanters in reptiles and mammals. - Amer. Mus. Natur. Hist., Bull. 38: 528-538.

HARRIS, J. (1998): A reanalysis of Acrocanthosaurus atokensis, its phylogenetic status, and paleobiogeographic implications, based on a new specimen from Texas. - New Mexico Mus. natur. Hist. Sci., 13: 1-75.

HARrison, C. J. O. \& WALKER, C. A. (1973): Wyleyia: a new bird humerus from the Lower Cretaceous of England. - Palaeontology, 16: 721-728.

Holtz, T. R. (1994): The phylogenetic position of the Tyrannosauridae: implications for theropod systematics. - J. Paleont., 68: 1100-1117.

- (1996): Phylogenetic taxonomy of the Coelurosauria (Dinosauria: Theropoda). J. Paleont. 70: 536-538.

Howse, S. C. B. \& MilneR, A. R. (1993): Ornithodesmus - a maniraptoran theropod dinosaur from the Lower Cretaceous of the Isle of Wight, England. - Palaeontology, 36: 425-437.

HuEne, F. vON. (1923): Carnivorous Saurischia in Europe since the Triassic. - Bull. Amer. Mus. Natur. Hist., 34: 449-458.

Hutt, S., Simmonds, K. \& Hullman, G. (1989): Predatory dinosaurs from the Isle of Wight. - Proc. Isle Wight Natur. Hist. archaeol. Soc., 9: 137-146.

Hutt, S., Martill, D. M. \& Barker, M. J. (1996): The first European allosaurid dinosaur (Lower Cretaceous, Wealden Group, England). - N. Jb. Geol. Paläont. Mh., 1996: 635-644; Stuttgart. 
Kirkland, J. I., Britt, B. B., Whittle, C. H., Madsen, S. K. \& Burge, D. L. (1998): A small coelurosaurian theropod from the Yellow Cat Member of the Cedar Mountain Formation (Lower Cretaceous, Barremian) of eastern Utah. - In: Lucas, S. G., Kirkland, K. I. \& EsteP, J. W. (Eds.): Lower and Middle Cretaceous Terrestrial Ecosystems., New Mexico Mus. Natur. Hist. Sci., Bull., 14: 239-248.

LYDEKKER, R. (1888): Catalogue of the fossil Reptilia and Amphibia in the British Museum. Pt. 1. Containing the orders Ornithosauria, Crocodilia, Dinosauria, Squamata, Rhynchocephalia, and Proterosauria. London (Brit. Mus. Natur. Hist.), p. 295.

- (1889): On a coeluroid dinosaur from the Wealden. - Geol. Mag., 6: 119-121.

- (1891): On certain ornithosaurian and dinosaurian remains. - Quart. J. Geol. Soc. London, 47: 41-44.

MADSEN, J. H. (1976): Allosaurus fragilis: a revised osteology. - Utah Geol. Min. Surv. Bull., 1091: 1-163.

Makovicky, P. \& SUES, H.-D. (1998): Anatomy and phylogenetic relationships of the theropod dinosaur Microvenator celer from the Lower Cretaceous of Montana. Amer. Mus. Novitates, 3240: 1-27.

NAISH, D. W. (1998a): Theropods eating theropods in the Wealden Group of England: evidence from a previously undescribed tibia. - In: JAGT, J. W. M., Lambers, P. H., Mulder, E. W. A. \& Schulp, A. S. (Eds.): Third European Workshop on Vertebrate Palaeontology: Programme and Abstracts: 56; Maastricht (Natuurhist. Musem).

- (1998 b): Predatory dinosaurs in England's Lower Cretaceous: crocodile heads, puffin snouts and the odd Lazarus taxon. - Newsl. Europ. Palaeont. Assoc., 13: 15 .

Norell, M. A., Clark, J. M., Dashzeveg, D., Barsbold, R., Chiappe, L. M., Davidson, A. R., McKenna, M. C., Perle, A. \& Novacek, M. J. (1994): A theropod dinosaur embryo and the affinities of the Flaming Cliffs dinosaur eggs. - Science, 266: 779-782.

Norman, D. B. (1980): On the ornithischian dinosaur Iguanodon bernissartensis from the Lower Cretaceous of Bernissart (Belgium). - Inst. Roy. Sci. Natur. Belg.) Mem., 178: 1-103.

- (1985): The Illustrated Encyclopedia of Dinosaurs. London (Salamander): 208.

- (1986). On the anatomy of Iguanodon atherfieldensis (Ornithischia: Ornithopoda). - Bull. Inst. Roy. Sci. Natur. Belg., Sci. Terre, 56: 281-372.

- (1987): Wealden dinosaur biostratigraphy. - In: Currie, P. J. \& Koster, E. H. (Eds.): Fourth Symposium on Mesozoic Terrestrial Ecosystems, Short Papers: 165-170; Drumheller (Tyrrell Mus. Palaeont.).

- (1990): Problematic Theropoda: "Coelurosaurs". In: Weishampel, D. B., Dodson, P. \& Osmolska, H. (Eds.): The Dinosauria: 280-305; Berkeley (Univ. Calif. Press).

Norell, M., Clark, J. M., Dashzeveg, D., Barsbold, R., Chiappe, L. M., Davidson, A. R. McKenna, M. C., Perle, A. \& NovaceK, M. J. (1994): A theropod dinosaur embryo and the affinities of the Flaming Cliff dinosaur eggs. - Science, 266: $779-782$.
Novas, F. E. (1996a): Alvarezsauridae, Cretaceous basal birds from Patagonia and Mongolia. - Mem. Queensl. Mus., 39: 675-702.

- (1996b): Dinosaur monophyly. - J. Vert. Paleont., 16: 723-741.

- (1997): Anatomy of Patagonykus puertai (Theropoda, Avialae, Alvarezsauridae), from the Late Cretaceous of Patagonia. - J. Vert. Paleont., 17: 137-166.

NovAs, F. E. \& PUERTA, P. F. (1997): New evidence concerning avian origins from the Late Cretaceous of Patagonia. - Nature, 387: 390-392.

Ostrom, J. H. (1970): Stratigraphy and paleontology of the Cloverly Formation (Lower Cretaceous) of the Bighorn Basin area, Wyoming and Montana. Peabody Mus. Natur. Hist. Bull., 30: 1-165.

- (1976 a): On a new specimen of the Lower Cretaceous theropod dinosaur Deinonychus antirrhopus. - Breviora, Mus. Comp. Zool. Harvard, 439: 1-21.

- (1976b): Archaeopteryx and the origin of birds. - Biol. J. Linn. Soc., 8: 91-182.

OWEN, R. (1857): Monograph on the fossil Reptilia of the Wealden and Purbeck Formations. Pt III. Dinosauria (Megalosaurus). - Palaeontogr. Soc. Monogr., 9: 1 -26.

- (1876): Monograph of the fossil Reptilia of the Wealden and Purbeck Formations. Suppl. 7. Crocodilia (Poikilopleuron), Dinosauria (Chondrosteosaurus). Palaeontogr. Soc. Monogr., 30: 1-7.

PAut, G. S. (1988): Predatory Dinosaurs of the World. New York (Simon \& Schuster): 464.

Pereda-Suberbiola, J. (1993): Hylaeosaurus, Polacanthus, and the systematics and stratigraphy of Wealden armoured dinosaurs. - Geol. Mag., 130: 767-781.

Perle, A., Chiappe, L. M., Barsbold, R., Clark, J. M. \& Norell, M. A. (1994): Skeletal morphology of Mononykus olecranus (Theropoda: Avialae) from the Late Cretaceous of Mongolia. - Amer. Mus. Novitates, 3105: 1-29.

SeELEY, H. G. (1882): On Thecospondylus horneri, a new dinosaur from the Hastings Sand, indicated by the sacrum and the neural canal of the sacral region. - Quart. J. Geol. Soc. London, 38: 457-460.

- (1887a): On Aristosuchus pusillus (Owen), being further notes on the fossils described by Sir. R. Owen as Poikilopleuron pusillus, Owen. - Quart. J. Geol. Soc. London, 43: 221-228.

- (1887b): On a sacrum apparently indicating a new type of bird, Ornithodesmus cluniculus Seeley from the Wealden of Brook. - Quart. J. Geol. Soc. London, 43: 206-211.

- (1888): On Thecospondylus daviesi (Seeley), with some remarks on the classification of the Dinosauria. - Quart. J. Geol. Soc. London, 44: 79-86.

- (1899): On evidence of a bird from the Wealden beds of Ansty Lane, near Cuckfield. - Quart. J. Geol. Soc. London, 55: 416-418.

Sereno, P. C. \& Arcucci, A. B. (1994): Dinosaurian precursors from the Middle Triassic of Argentina: Marasuchus lilloensis, gen. nov. - J. Vert. Paleont., 14: 53-73.

Sereno, P. C. Beck, A. L., Dutheil, D. B., Gado, B., Larsson, H. C. E., Lyon, G. H., Marcot, J. D., Rauhut, O. W. M., Sadleir, R. W., Sidor, C. A., Varricchio, D. D., WILsON, G. P. \& WiLson, J. A. (1998): A long-snouted predatory dinosaur from Africa and the evolution of Spinosauroids. - Science, 282: 1298-1302. 
Sereno, P. C., Dutheil, D. B., Iarochene, M., Larsson, H. C. E., Lyon, G. H., Magwene, P. M., Sidor, C. A., Varricchio, D. J. \& Wilson, J. A. (1996): Predatory dinosaurs from the Sahara and Late Cretaceous faunal differentiation. Science, 272: 986-991.

Stovall, J. W. \& LANGSTon, W. (1950): Acrocanthosaurus atokensis, a new genus and species of Lower Cretaceous Theropoda from Oklahoma. - Amer. Midl. Natur., 43: 696-728.

SuEs, H.-D. (1997): On Chirostenotes, a Late Cretaceous oviraptorosaur (Dinosauria: Theropoda) from western North America. - J. Vert. Paleont., 17: 698-716. Welles, S. P. (1984): Dilophosaurus wetherilli (Dinosauria, Theropoda), osteology and comparisons. - Palaeontographica, A. 184: 85-180; Stuttgart.

Manuscript received: April 20, 1999.

Revised version accepted by the Tübingen editors June 1, 1999.

\section{Address of the author:}

DARREN NAISH, Palaeobiology Research Group, School of Earth, Environmental and Physical Sciences, University of Portsmouth, Burnaby Building, Burnaby Road, Portsmouth P01 3QL England.

E-Mail: darren.naish@port. ac.uk 